\title{
Revista de Educação Física: ciclo de vida, seção unidade de doutrina e lição de educação física ( 1932-2002)
}

\author{
Amarílio Ferreira Neto* \\ Ediane de Melo Maia \\ Magda Terezinha Bermond
}

\begin{abstract}
Resumo: Objetiva elaborar o ciclo de vida da Revista de Educação Física no período de 1932 a 2002; analisar as seções Unidade de Doutrina e Lição de Educação Física, identificando os eixos doutrinários e pedagógicos, e ainda como são prescritos e praticados no Exército e na escola. A orientação teórico-metodológica assume o periódico como objeto e fonte. Os resultados indicam as características do periódico materializadas no ciclo de vida. Os eixos pedagógicos são: continuidade, alternância, graduação, atração e disciplina, que se encontram subordinados aos eixos doutrinários: hierarquia, ordem e disciplina. A Lição de Educação Física é distinta para militares e escolares.

Palavras-chave: Educação Física, Periódicos, Exército, Escola.
\end{abstract}

O estudo de impressos de variada tipologia tem recebido força, também, na área de Educação Física. Todavia, deve-se reconhecer que, ainda, há um vácuo na investigação dos projetos editoriais de nossa área, quer seja na forma de livro, quer seja em formato de periódico: revista e jornais. Conhecer tais impressos em sua intimidade material requer olhá-los na sua condição de objeto e núcleo de informações temáticas (fonte).

Nesta investigação foi estudado o ciclo de vida, as seções Unidade de Doutrina e Lição de Educação Física da Revista de Educação Física da Escola de Educação Física do Exército no período de 1932 a 2002. Para tanto, as seguintes questões conduziram o exame do corpus de pesquisa: quais são os elementos caracterizadores

*Universidade Federal do Espírito Santo; Coordenador do PROTEORIA: Instituto de Pesquisa em Educação e Educação Física.

**Bolsistas do PIBIC-CNPq-UFES.

Movimento, Porto Alegre, v. 9, n. 1, p. 91-118, janeiro/abril de 2003 
do periódico em termos de duração, periodicidade, agentes responsáveis, colaboradores, recorrências e predominâncias temáticas? Quais são os eixos doutrinários e pedagógicos propostos pelo Exército como estratégia de disseminação da Educação Física na sociedade brasileira e, em particular, no âmbito escolar, presentes na seção Unidade de Doutrina da Revista de Educação Física? Como a seção Lição de Educação Física expressa o processo de transformação dos eixos pedagógicos em objetivos, conteúdos, metodologia, recursos físicos, materiais didáticos e avaliação da Educação Física como componente curricular para o cotidiano da escola?

\section{Recursos Teórico-Metodológicos no Estudo de Impressos da Educação e da Educação Física}

Esta pesquisa é mais um desdobramento de recente estudo que teve como objetivo discutir o pensamento pedagógico dos militares do Exército para a Educação Física no período de 1880 a 1950, tendo como fontes primordiais a revista $A$ Defesa Nacional e Revista de Educação Física (Ferreira Neto, 1999). Corolários desse esforço associam-se, também, os estudos sobre: currículo em periódicos (Aroeira, 2000; Aroeira; Ferreira Neto, 2001); avaliação educacional em periódicos (Santos, 2002); avaliação de periódicos científicos (Nascimento, 2002); e estratégias editoriais e proposições educacionais na Revista de Educação Physica (Schneider, 2003).

Pode-se afirmar que esta pesquisa emerge de um contexto de estudos mais amplo chamado A constituição de teorias da Educação Física no Brasil: o debate em periódicos no século XX (Ferreira Neto et al., 2000ab; 2002ab).

São tributários desse esforço de compreensão temática da Educação Física brasileira, por meio de fontes periódicas, com as devidas e necessárias nuanças de fundo teórico-metodológico, Lima (1980), Bercito (1991), Goellner (1999) e Oliveira (2001a).

Na História e na Educação, que já possuem produção consolidada, tanto no uso do periódico como objeto (Cruz, 1997; Catani; Souza, 1999; Martins, 2001; Biccas, 2001) como na condição de fonte privilegiada (Catani, 1989; Catani, 1994; Catani; Bastos, 1997), o debate concentrou-se, recentemente, na busca de definição com maior rigor de critérios de qualidade da produção historiográfica. Concentra-se esforço nos cuidados

Movimento, Porto Alegre, v. 9, n. 1, p. 91-118, janeiro/abril de 2003 
a serem observados pela comunidade de pesquisadores, com o uso, sem o devido diálogo com a base teórico-metodológica, de fontes, periodização e categorias propostas. Nunes (2000, p. 11) é enfática:

Não posso responder pelos outros, mas aceito o desafio de recolocaro problema a partir do meu estágio de entendimento das questôes com as quais lido ao produzir história da educação.

Do meu ponto de vista, tanto as fontes, quanto a periodização e as próprias categorias não estão dadas. São resultado de um laborioso trabalho do investigador. Os objetivos e as hipóteses que dirigem a investigação norteiam o recorte do tema e com ele a problematização do objeto, que já pressupõe localização e escolha de certas fontes, a periodização desejada e as categorias a serem utilizadas. Ou seja, o historiador vai construindo o seu campo de significado ao transitar por um circuito múltiplo de instituições, tradições teóricas, fontes e resultados de pesquisa, num esforço contínuo através do qual não só constitui suas fontes, mas estabelece estratégias e práticas interpretativas.

O perfil teórico-metodológico desta pesquisa observou os confrontos e mediações ocorridos na evolução dos periódicos da Educação Física (Ferreira Neto et al., 2002ab), na categoria da longa duração (Bloch, 2001) e na seleção e uso das fontes (Ferreira Neto, 2000ab).

A base teórica da pesquisa sustenta-se, também, nas concepções de materialidade, indícios, sinais, emblemas, estilo (inclusão e exclusão), imagem, representação, distância (longe/ perto), retórica, prova e história de Ginzburg (1991, 1999, 2001, 2002). A materialidade assenta-se no que está impresso no periódico objeto e fonte da pesquisa o que descarta qualquer possibilidade de retórica (entendida como construção de argumentos desprovidos de provas documentais variadas). História se faz com e a partir de testemunhos; o trabalho de pesquisa histórica se inviabiliza sem fontes. O estilo com freqüência é utilizado para delimitar e cortar fontes por exclusão. Aqui essa posição é inadmissível, uma vez que o que está materializado no impresso já foi incluído como indício, sinal, emblema do processo histórico complexo que precisa ser captado nos termos prescritos por seus editores/autores. Os testemunhos devem ser submetidos à crítica por comparação e contradição, donde se extrai que eles não são a História, mas permitem, a partir deles, a construção/ identificação de indícios, sinais, emblemas passíveis de explicar um determinado objeto de estudo. A representação se refere à presença e à ausência, o que se pretendeu deixar ver e o que não se quer que veja. Essa posição sobre representação torna inviável a criação de mitos (porque eles simplesmente não existem na

Movimento, Porto Alegre, v. 9, n. 1, p. 91-118, janeiro/abril de 2003 
Educação Física brasileira) e simultaneamente rejeita a mitologia como discurso agressivo (supostamente crítico) feito em nome da razão contra um saber tradicional (ainda) indeterminado. A imagem é vista aqui tanto como "retrato", uma unidade estática, como numa série de imagens sobre o mesmo objeto no tempo, o que nos permite tanto captar o detalhe pontualmente quanto ao movimento sinalizado na seqüência de imagens. A distância buscada é aquela que põe o historiador no lugar da mais adequada compreensão do objeto em análise, o que evita a indiferença, a compaixão e o julgamento.

Foram utilizadas as diretrizes para estudo da imprensa periódica indicadas por Catani e Sousa (1999), uma vez que a Revista de Educação Física será abordada como objeto de estudo e como focus documental para discutir sobre seu ciclo de vida, seus eixos doutrinários e pedagógicos na seção Unidade de Doutrina e o processo de transformação dos eixos doutrinários e pedagógicos em prática cotidiana na Educação Física Escolar dentro da seção Lição de Educação Física.

Deve-se, então, estar atento aos documentos que, como afirma Bloch (2001, p. 79),

[...] mesmo os aparentemente mais claros e mais complacentes, não falam senão quando sabemos interrogá-los [...], toda investigação histórica supõe, desde seus primeiros passos, que a busca tenha uma direção [...], nunca a observação passiva gerou algo de fecundo.

No processo de organização e sistematização dos testemunhos, construiu-se um banco de dados da Revista de Educação Física, o qual possibilitou o cruzamento de informações relevantes ao estudo, facilitando, assim, seu desenvolvimento. Para a construção desse banco de dados, foram utilizadas informações contidas no Catálogo de Periódicos de Educação Física e Esporte (1930-2000), cujos dados foram passados para uma tabela em Word, que, por fim, foi transferida para o Excel e, em seguida, para programa Access, ${ }^{1}$ o qual nos permite maior mobilidade e facilita o cruzamento das informações.

\footnotetext{
1 No banco de dados estão contidos os seguintes campos: autor, dados sobre o autor, título, nome da revista, local, ano/volume, número, página, mês, data, nome da seção, temas, palavras-chave1, palavras-chave2, resumo, observações, bibliografia, autores citados ou indicados, expediente, capa, imagens, propagandas e instalações esportivas. Rico em fontes iconográficas, o periódico terá suas imagens escaneadas ou fotografadas com câmera digital para, posteriormente, serem transferidas para o banco de dados. Essas imagens são fundamentais para a análise e compreensão da revista, pois por meio delas pode haver uma comparação entre o que está escrito e o que elas demonstram.
}

Movimento, Porto Alegre, v. 9, n. 1, p. 91-118, janeiro/abril de 2003 
Ao abordarem as reflexões que tratam dos pressupostos essenciais das metodologias propostas para a análise de textos em pesquisa histórica, Cardoso e Vainfas (1997, p. 377) afirmam:

[...] um documento é sempre portador de um discurso que, assim considerado, não pode ser visto como algo transparente. Ao debruçar-se sobre o documento, $o$ historiador deve sempre atentar, portanto, para o modo através do qual se apresenta o conteúdo histórico que pretende examinar, quer se trate de uma simples informação, quer se trate de idéias.

Os autores indicam, ainda, que a história não se reduz à estrutura do texto e que tampouco deve ser desprezada para uma análise do conteúdo histórico-social do discurso. Cabe-nos inventariar alguns métodos e técnicas que podem auxiliar a decifração da semântica do texto como portador de valor histórico.

É importante ressaltar que o processo de levantamento de dados em fontes primárias precisa estar claramente orientado pelos objetivos do estudo. Gomes (1981, p. 259) afirma que

[...] esta é, não só a primeira condição, como a condição sine qua non de um bom trabalho com fontes, quer sejam elas primárias ou secundárias. Assim, devido a sua importância e complexidade, a etapa de levantamento de dados requer do pesquisador uma reflexão permanente sobre a fonte, capaz de evitaro mito da minúcia como símbolo de eficiência ou ainda de aceitar a lógica da fonte como a lógica de seu próprio objeto de estudo.

Numa busca efetuada de revista a revista, encontraram-se doze textos da seção Unidade de Doutrina, publicados em períodos distintos. Os primeiros artigos aparecem seqüencialmente da revista de n. 2, de junho de 1932, à revista de n. 7, de abril de 1933, apresentando, a partir de então, um período de supressão e só voltando a ser publicada na revista n. 40, de julho de 1938, permanecendo em intervalos irregulares até o n. 47, de dezembro de 1939. Esses textos foram escritos pelo tenente- coronel Newton Cavalcanti, pelo capitão Ilidio Romulo Colonia e pelo capitão Jair Jordão Ramos. Foi efetuada também uma busca na revista por artigos escritos por esses autores e verificou-se que o tenente-coronel Newton Cavalcanti escreveu seis artigos para a revista, o capitão Ilídio Romulo Colonia quatro e o capitão Jair Jordão Ramos cinqüenta e três.

No levantamento referente à seção Lição de Educação Física, registraram-se quarenta e três textos relacionados com a seção, dos quais vinte e quatro possuem o título Lição de Educação Física, treze aparecem com o título Lições de Aplicações Militares e seis com nomes diversos, por exemplo, Ataque e Defesa.

Movimento, Porto Alegre, v. 9, n. 1, p. 91-118, janeiro/abril de 2003 
Para tanto, além do estudo dessas seções, com o intuito de melhor compreendê-las, lembrando que [...] compreender nada tem de uma atitude de passividade [...] (Bloch, 2001, p. 128), serão consultados, também, outros textos presentes na revista, como os Editoriais e correlatos necessários. Procurou-se sempre repensar as dificuldades e a importância do "relacionamento" do pesquisador com as fontes de seu trabalho (Gomes, 1981) e buscou-se sempre interrogá-las exaustivamente.

Indícios da Materialidadeda RevistadeEducação Física(1932-2002)

[...] ao avaliar as provas, os historiadores deveriam recordar que todo ponto de vista sobre a realidade, além de ser intrinsecamente seletivo e parcial, depende das relações de força que condicionam, por meio da possibilidade de acesso à documentação, a imagem total que uma sociedade deixa de si. Para 'escovar a história ao contrário' [...] como Walter Benjamin exortava a fazer, é preciso aprender a ler os testemunhos às avessas, contra as intenções de quem os produziu. Só dessa maneira será possível levar em conta tanto as relações de força quanto aquilo que é irredutível a elas (Ginzburg, 2002, p. 43).

\section{Sobre o Ciclo de Vida (1932-2002)}

O ciclo de vida da Revista de Educação Física se presta a estabelecer a materialidade especialmente descritiva de sua composição editorial no tempo. Os indícios iniciais a seguir são fundamentais à compreensão do conjunto do periódico. Os indicadores de referência foram adaptados de Cruz (1997):

F Chancela: Escola de Educação Física do Exército.

F Objetivo: divulgação da "causa da Educação Física", em especial do Regulamento de Educação Física.

F Ciclo de Vida: 1932-2002; números: 1 ao 125 (o número 95 não existe); quantidade de artigos catalogados: 2.124.

F Periodicidade: pode ser caracterizada como variável, dado que é possível afirmar que, em diferentes tempos, a revista foi mensal, bimestral, quadrimestral, semestral.

F Formato, Colunagem: formato próximo ao A4 e colunagem variável, inclusive no mesmo exemplar: diagramação em página inteira, dupla coluna, tripla coluna e, em menor ocorrência, dupla página aberta (imagens, por exemplo).

F Número de Páginas: variável. Todavia, pode-se indicar um número aproximado de 40 páginas por exemplar, contadas de capa a capa.

Movimento, Porto Alegre, v. 9, n. 1, p. 91-118, janeiro/abril de 2003 
F Propriedade: Estado Maior do Exército.

F Expediente (diretores, gerentes, secretários): oficiais do Exército.

F Colaboradores: militares de diferentes patentes com prevalência de oficiais e civis de variada importância e funções sociais na sociedade. Presença de autores brasileiros e estrangeiros.

F Âmbito de circulação: predominantemente nacional em setores militares e civis.

F Tiragem: variável. Entre 2.000 e 5.000 exemplares.

F Preço (avulso e/ou assinatura): preço variável e aquisição avulsa ou por assinatura. Há evidências de distribuição gratuita.

F Preço de espaço publicitário: variável. A referência determinante do preço é o tamanho do espaço, local e quantidade de cores. A revista oferece um oitavo de página, três quartos, um quarto de página, meia página, uma página e uma coluna.

F Conteúdo (assuntos recorrentes):

G Educação Física e Biologia;

G Educação Física e Psicologia;

G Educação Física e Sociologia;

G Educação Física e Filosofia;

G Educação Física e História;

G Educação Física e Pedagogia;

G Educação Física e Epistemologia;

G Ginástica;

G Métodos Ginásticos; Esportes;

G Jogos;

G Danças;

G Lutas;

G Formação do Professor;

G Ensino Primário (Educação Física de $1^{\mathrm{a}}$ a $4^{\mathrm{a}}$ série);

G Ensino Secundário (Educação Física de $5^{\mathrm{a}}$ a $8^{\mathrm{a}}$ série);

G Ensino Industrial (Educação Física no Ensino Médio);

G Ensino Comercial;

G Ensino Emendativo (Educação Física Adaptad);

G Ensino Superior;

G Play-grounds, Parques Infantis e Colônias de Férias;

Movimento, Porto Alegre, v. 9, n. 1, p. 91-118, janeiro/abril de 2003 
G Esportes Aquáticos;

G Basquetebol;

G Voleibol;

G Handebol;

G Futebol;

G Tênis;

G Esgrima;

G Hipismo;

G Construção de Instalações Esportivas;

G Legislação;

G Políticas Públicas;

G Treinamento Físico Militar e Desportivo;

G Biomecânica;

G Jogos Olímpicos;

G Educação Física Feminina;

G Tiro;

G Educação Física Militar;

G Ginástica Rítmica;

G Ciclismo;

G Escotismo;

G Relatórios de Eventos;

G Associações de Representação de Categoria;

G Notícias;

G Bibliografia.

F Iconografia: uso freqüente de fontes iconográficas variadas. Pode-se afirmar que é a mais importante referência de uso desse tipo de fonte em periódicos de nossa área no século XX.

F Publicidade: divulgação irrestrita de todo tipo de produto. Exemplo: pólvora, armas e munição, charuto, cigarro, bebidas alcoólicas, refrigerantes, movelaria, alfaiataria, equipamentos médicos, medicamentos, aparelhagem de ginástica, roupas esportivas, academia, etc. Referência singular que pode ajudar na compreensão do uso de publicidade em periódicos científicos na atualidade.

F Acervo: coleção completa na Escola de Educação Física do Exército e no PROTEORIA.

Movimento, Porto Alegre, v. 9, n. 1, p. 91-118, janeiro/abril de 2003 


\section{Sobre a seção Unidade de Doutrina}

Foram encontrados doze textos referentes à seção Unidade de Doutrina na Revista de Educação Física, sendo três deles escritos pelo tenente-coronel Newton Cavalcanti, três pelo capitão Ilidio Romulo Colônia e seis pelo capitão Jair Jordão Ramos. Essa seção foi escrita somente por oficiais, os quais têm por função criar e manter a doutrina que garante a existência do Exército e cuidar para que ela seja cumprida.

Antes de iniciar a discussão sobre a seção Unidade de Doutrina, torna-se necessário um esclarecimento sobre o que o exército entende por pedagogia e o que se considerou eixos doutrinários e eixos pedagógicos nesta pesquisa.

Segundo Silva (apud Ferreira Neto, 1999, p. 65),

[...] a pedagogia abrange praticamente a vida. Não se limita a satisfazer a nossa imperiosa necessidade de conhecer fatos e explicá-los; ela toca a ação humana, modificando-a e melhorando-a com as suas normas traçadas, elevando-a, procurando tornar mais perfeitos os afazeres humanos, tirando-lhes vagarosamente os inconvenientes, subtraindo o inútil e corrigindo-lhes os erros. Ohomem, como saber, consegue derrubar obstáculos gigantescos; ele não considera o saber um prêmio último e independente, mas, sim, um meio firme e certo para aumentar o seu poder, fazendo em todas as ocasiões, valer a sua vontade. A origem do saber é uma necessidade prática; é uma contribuição, um auxílio para aumentar e aperfeiçoar a atividade na vida. Pedagogia então não é ciência simplesmente teórica. Pedagogia é o estudo da educação, com o fim de se tirarem regras que sirvam para a aplicação prática. O progresso intelectual, moral e técnico não desaparece em virtude da educação.

Pinheiro (1933b) $)^{2}$ afirma:

A Pedagogia é a ciência da educação, abrange dois aspectos: o que se refere à realidade e o que se refere ao ideal.

Para que a obra educativa seja realizada com o máximo de rendimento énecessário que ela se apóie, preliminarmente, em conhecimentos proporcionados por um grupo de ciências que dão lugar a essa realidade e a esse ideal. ${ }^{3}$

2 As citações de 1932 e 1933 não apresentam página, pois a fonte não é numerada, além dos textos das citações diretas terem sido mantidos conforme o original.

3 As disciplinas que ofereciam suporte teórico à prática da Educação Física eram: a Biologia, a Sociologia, a Psicologia, a Filosofia e a História. O aporte teórico articulado a partir de tais disciplinas repercutiria na concepção de Pedagogia, Didática e Metodologia aplicadas à Educação Física. Ver: MARINHO, Inezil Penna. Conceito bio-sócio-psicofilosófico da educação física em oposição ao conceito anátomo-fisiológico. Revista Brasileira de Educação Física, Rio de Janeiro, ano 1, n. 2, p. 23-38, fev. 1944. E também: MARINHO, Inezil Penna. Pedagogia, didática e metodologia: estudo das características próprias a cada qual. Arquivos da ENEFD, Rio de Janeiro, ano 6, n. 6, p. 23-46, jan. 1953.

Movimento, Porto Alegre, v. 9, n. 1, p. 91-118, janeiro/abril de 2003 
Ferreira Neto (1999, p. 25) expõe, ainda, que

[...] uma Pedagogia aplicada no interior do Exército, está condenada a favorecer à manutenção da hierarquia e da disciplina militar [....; a atender a especificidade institucional, istoé, todo componente pedagógico deve coadjuvar para elevaro nível de preparação da tropa para fazer a guerra; e a ser uma Pedagogia da ação prática.

Isso leva a acreditar que o Exército apresenta uma pedagogia cuja categoria central é a experiência do aprender fazendo ou do fazer para aprender. ${ }^{4}$ De acordo com Pinheiro (1933b), [...] aprender na forma educativa moderna é ter experiência. Já para Dewey (1978, p. 34),

[...] só se aprende o que se pratica - Seja uma habilidade, seja uma idéia, seja um controle emocional, seja uma atitude ou uma apreciação, só as aprendemos se as praticarmos.

Nesse contexto da Educação Física, percebe-se que [...] os Regulamentos do ensino no Exército foram grifados por duas formulações: a objetividade do ensino e a praticidade dos métodos e processos (Ferreira Neto, 1999, p. 35).

Nesta pesquisa, entende-se como eixos doutrinários as grandes linhas orientadoras das práticas prescritas no Exército, as quais devem estar presentes em todas as manifestações da instituição, associadas aos eixos pedagógicos, que são específicos para cada disciplina (matéria). Assim como existem os eixos pedagógicos a serem aplicados na Educação Física, também existem os específicos para Matemática, Fisiologia, entre outros. Os eixos pedagógicos são subordinados aos eixos doutrinários, pois estes últimos orientam toda a doutrina existente no Exército.

A compreensão desses eixos precede o conhecimento dos objetivos e práticas prescritas materialmente pelo impresso objeto e fonte da pesquisa. Para Molina (1932), os objetivos e práticas do trabalho físico desenvolvem, harmonizam e integralizam todas as nossas funções orgânicas. Além disso, o exercício físico

[...] desenvolve a força, a destreza, a resistência, a velocidade, a harmonia de formas, a coragem, a audácia, o sangue frio, a tenacidade, em quatro palavras: a tempera de caráter (Molina, 1932).

\footnotetext{
4 Existe no Exército nessa época um esforço de modernização do ensino, o qual deve privilegiar o ensino prático sobre o teórico. Mais detalhes em: Ferreira Neto Amarílio. Os militares e a Educação. In: Ferreira Neto. A pedagogia no exército e na escola: a educação física brasileira (1880-1950). Aracruz, ES: FACHA, 1999. p. 25-40.
}

Movimento, Porto Alegre, v. 9, n. 1, p. 91-118, janeiro/abril de 2003 
Diante de todas essas vantagens trazidas pelo trabalho físico, tornou-se indispensável a discussão da importância da Educação Física para um povo e, muito principalmente para o nosso, que era considerado uma [...] sub-raça [...], uma multidão de indivíduos tristes de mau temperamento, nervosos (Pinheiro, 1933a). Além disso, nessa época, a Educação Física é vista como uma necessidade dos povos civilizados e sua adoção traria vantagens imediatas que refletiriam em todo o País e traria [...] como conseqüência o acréscimo das forças produtivas, aumento considerável do rendimento do trabalho individual e coletivo, fechamento de hospitais e presídios, e a formação e melhoramento da nossa raça (Molina, 1932).

Assim sendo, fez-se necessária a escolha de um método que fundamentasse as práticas da Educação Física na sociedade brasileira. Na impossibilidade de apresentar um que fosse brasileiro, restou à Escola de Educação Física do Exército estudar todos os existentes e escolher o que mais seria útil aos seus propósitos.

Segundo Molina (1932),

Ométodo a ser adotado deve ser geral, istoé, servir para qualquer idade ou sexocom variantes, mas dentro de uma única diretiva -; ser [fisiológico], isto é, basear-se no conhecimento perfeito das ações e reações orgânicas nas diferentes idades em face do exercicio fisico; ser atraente, meio psicologico e pedagógico, de obter-se a persistência dos praticantes.

A todos esses requisitos satisfaz o método francês, daí sua adoção.

É este métodocientífico-fisiológico e psicológico-idealizada para uma raça latina como a nossa que nós adotamos.

Pode-se constatar, então, que a Seção Unidade de Doutrina apresenta propostas para a prática da Educação Física, fundamentadas no Regulamento Geral de Educação Física. Por meio desse Regulamento, é feita uma interpretação, que é divulgada e colocada em prática pelos profissionais que ministram a Educação Física tanto no meio militar quanto no civil.

Pensamos prestar, por esta fórma, algum serviço à correta aplicação do método adotado, de acordo com a interpretação do C.M.E.F. [Centro Militar de Educação Física], que, por todos os motivos, deve ser o guia geral nos assuntos atinentes à educação física em nosso país (Colonia, 1933).

5 Aí reside uma polêmica que necessita ser enfrentada com rigor teóricometodológico em nossa área. O projeto e prescrições para a área de Educação Física que foi interpretado como sendo exclusivamente produção militar, quando utilizado o referencial ginzburguiano acima referido, o que se obtém é uma convivência material de militares e civis dentro do impresso de cordialidade, cooperação e complementaridade em favor da "causa nacional da Educação Física". Posicão similar é compartilhada por Oliveira (2001a) ao estudar a Revista Brasileira de Educação Física e Desportos durante a ditadura militar (1968-1984).

Movimento, Porto Alegre, v. 9, n. 1, p. 91-118, janeiro/abril de 2003 
Pela análise dessas propostas, verificou-se que

O ensino da educação física é ministrado sob a forma de lições completas, abrangendo as sete familias [marchar; trepar, escaladas e equilibrio; saltar; transportar e carregar; correr; Lançar; atacar e defender] com o objetivo de conseguir o desenvolvimento harmonioso do corpo; de sessões de jogos, destinada a substituir as lições uma ou duas vezes por semana, de sessões de esporte individuais e coletivos, que servem para o ensino e a prática de estilo e das regras e tática de cada um dêles, por fim, as sessões de estudo destinadas a preparar as lições completas de educação fisica geral e as desportivas (Cavalcanti, 1932a).

As lições de Educação Física são reuniões de exercícios variados e combinados que interessam simultaneamente ou mesmo sucessivamente a todos os órgãos do corpo ou às suas grandes funções, tendo como objetivo o seu aperfeiçoamento e a sua melhoria. Todas as lições ${ }^{6}$ iniciam-se por uma sessão preparatória, passando pela lição propriamente dita e terminando com a volta à calma.

Os planos apresentados pela Escola de Educação Física do Exército para se ministrarem as aulas de Educação Física são bastante detalhados, incluindo desde a preparação material até a aula propriamente dita. Toda lição de educação fisica deve ser preparada com antecedencia [...] nada deve ser improvisado; tudo deve ser previsto (Cavalcanti, 1932a). Assim, organizadas as lições, de modo a formar uma série de lições de dificuldades crescentes, passa-se a estudar cada uma delas por meio de sessões de estudo. Completa a preparação material [...] a locação de um estrado em que o guia possa ser visto por todos, ou então para ser ocupado pelo instrutor para ter uma vista sobre o conjunto (Cavalcanti, 1932b).

O caráter organizativo da aula é colocado em evidência da seguinte forma: [...] tal preparação material é a alma da lição completa e, sem éla, não se poderá satisfazer o principal principio - a continuidade (Cavalcanti, 1932b, grifo nosso).

A lição é contínua quando não é interrompida por repouso algum. Esta continuidade é necessária, porque o fim procurado não é sómente agir sobre cada orgão tomado separadamente, mas tambem, eprincipalmente, obter um efeito de conjunto sobre o organismo (Estado Maior do Exército, 1934, p. 15).

6 Todavia, nas lições, os objetivos, conteúdos, metodologia, recursos físicos, materiais didáticos e avaliação são diferentes conforme a instituição: Exército ou escola. Essa assertiva pode ser conferida no impresso tanto na descrição das lições como nas imagens (fotografia e crokiart).

7 Um auxiliar munido de um relógio avisa ao instrutor o término dos tempos destinados aos vários exercícios, enquanto outro auxiliar circula entre as filas para corrigir eventuais erros na execução dos movimentos. Essa prática e auxílio são exclusivos da Educação Física militar.

Movimento, Porto Alegre, v. 9, n. 1, p. 91-118, janeiro/abril de 2003 
Outro princípio que deve ser seguido para a composição das lições é que ela deve ser alternada, ou seja, a lição deve ser composta por exercícios que mobilizem as partes superior e inferior do corpo.

Esse princípio, segundo Cavalcanti(1932b):

Serve para dar desenvolvimento harmonioso ao corpo pelo equilibrio do mesmo número de exercícios de braços e pernas e dando ainda aos membros um relativo repouso durante o tempo de espera da execução do outro membro. Este modo de proceder evita a fadiga muscular que resultaria do trabalho continuado de uma mesma parte do corpo.

A graduação da lição em intensidade e dificuldade constitui o terceiro princípio que, para ser alcançado, exige a organização de um plano geral de ensino, no qual são previstas lições mais intensas, compostas de elementos de dificuldade crescente.

De acordo com Cavalcanti (1932b),

Sua graduação em intensidadeéatingida quando são seguidos no decorrer da lição a ordem das familias dos exercícios onde essa exigência está satisfeita. Aíencontramse os exercícios classificados em ordem de energia crescente até, mais ou menos, a metade da lição propriamente dita, para depois decrescer atéo fim da lição.

A atração da lição constitui o quarto princípio. O método francês preconiza o interesse, dizendo que a lição de educação física deve ser atraente (Pinheiro, 1933b, grifo do autor).

Conforme Dewey (1978, p. 63), o interesse é [...] a garantia única de atenção; se conseguirmos interesse para uma série de fatos ou idéias, podemos estar certos de que o aluno empregará todas as suas energias em compreendê-los e assimilá-los.

O autor afirma ainda:

[...] obtém-se interesse, exatamente, não se pensando enão se buscando conscientemente consegui-lo; mas, ao invés disto, promovendo as condições queo produzem (1978, p. 113).

A lição éatraente quando os exercícios de cada família são freqüentemente variados, quando os jogos são introduzidos na lição no momento oportuno e quando o instrutor, por seu exemplo e sua atividade, sabe manter a alegria na sua escola (Estado Maior do Exército, 1934, p. 16).

Esse princípio é de grande importância e a sua execução depende do grau de habilidade do instrutor, [...] só torna uma lição atraente, o instrutor que está integrado no seu papel e tem segurança de seu saber e conhecimento de seus alunos. Deste conhecimento resulta a introdução de meios destinados a tornar a lição agradável (Cavalcanti, 1932b).

Movimento, Porto Alegre, v. 9, n. 1, p. 91-118, janeiro/abril de 2003 
Ainda de acordo com Cavalcanti (1932b)

[...] a turma éoreflexo do instrutor e, um instrutor entusiasta e apaixonado pelo assunto que transmite, é, em geral, bem sucedido. Oinstrutoréo espelho dos seus alunos. Uma classe sem vivacidade denota a insuficiência do instrutor que a dirige.

Aguayo (1964) argumenta que a personalidade e as atividades mentais do professor contribuem para despertar o interesse e, em conseqüência, a atenção da criança. As atitudes e emoções do professor são muito contagiantes, logo, um professor alegre, animado, costuma ter alunos atentos e interessados.

Para que a lição se torne mais agradável, pode haver a [...] variação dos exercicios ou a introdução de jogos (Cavalcanti, 1932b). De acordo com Ramos (1938, p. 52),

O instrutor deverá, pois, esforçar-se para tornar atraentes as sessões de trabalho físico, pela escolha judiciosa de exercícios variados, freqüentemente, pela introdução dos jogos no momento oportuno (no decorrer da lição), e principalmente, pela emulação e disposição para o trabalho, que provocará em sua turma.

Por fim, o Regulamento exige que a lição seja disciplinada, como último princípio.

A lição é disciplinada se os exercícios previstos são comandados sem hesitação, se se desenrolam normalmente e se são executados com a intensidade e a energia desejáveis por uma escola atenta (Estado Maior do Exército, 1934, p. 16).

Esse princípio é alcançado pelo saber do instrutor,

[...] cuja ilustração permite que ele não vacile na direção da lição pela confiança que impóe aos alunos que instrue, conseguindo, com habilidade, prender a atenção destes e incentivá-los à execução correta dos movimentos (Cavalcanti, 1932b).

Os princípios de continuidade, alternância, graduação, atração e disciplina devem ser seguidos nas formulações das lições e devem existir também na sua execução. Seu emprego ocorre com a finalidade de [...] desenvolver no espírito dos alunos qualidades de ordem geral que contribuem para o enriquecimento de suas qualidades morais (Cavalcanti, 1932b), moldando-os, dessa forma, de acordo com as exigências do Exército.

Como cita Rolim (1935, p. 35),

[...] a educação física pode ser considerada não só como uma preparação física para a guerra, como também uma preparação moral, visto como a vida do soldado em campanha consiste, tanto em resistir à fadiga como em vencer os sofrimentos eem desprezar os perigos.

Movimento, Porto Alegre, v. 9, n. 1, p. 91-118, janeiro/abril de 2003 
Considerados base para a fundamentação das lições e eixos pedagógicos específicos para aplicação na Educação Física, devem estar presentes na execução de todas as aulas de Educação Física, sejam elas ministradas em escolas militares, sejam em escolas civis. Esses princípios apresentam-se subordinados aos eixos doutrinários existentes no Exército, os quais orientam toda a doutrina institucional, são eles: a hierarquia, a ordem e a disciplina.

A educação militar considera fundamental o princípio da disciplina, que é a completa submissão aos preceitos regulamentares e a obediência, sem hesitação, ao oficialato. De acordo com a doutrina do Exército, a disciplina é um desdobramento das forças físicas, morais, intelectuais e psicológicas. Sendo assim, as propostas pedagógicas aplicadas no Exército e sugeridas por ele tendem a favorecer a utilização da hierarquia, da ordem e da disciplina, que estão mutuamente relacionadas.

Há sensíveis diferenças na maneira como é encarada a Educação Física nas escolas e no meio militar. As atividades físicas no meio militar visam, em última análise, a preparação do soldado para a guerra (Ramos, 1953, p. 3). Objetivam que o soldado atinja elevado grau de aperfeiçoamento físico e de bem-estar moral, que são condições indispensáveis ao melhor desempenho de suas funções profissionais, por meio de processos bastante objetivos (Ramos, 1953).

Esta seção, Unidade de Doutrina, no que se refere à Educação Física Militar, propõe-se a divulgar uma verdadeira orientação ${ }^{8}$ a ser dada a esse ramo educacional, visto que

[...] a educação física nos corpos de tropa tem dado margem a interpretações que não estão de acordo nem com a letra, nem com o espírito do Regulamento (Revista de Educação Física, 1933).

A Educação Física militar divide-se em duas partes bem distintas: a primeira consiste de Educação Física geral, por meio da qual se preparam ou mesmo aperfeiçoam fisicamente os jovens, fornecendo meios para se adaptarem às funções do soldado; na segunda parte, o treinamento físico é relativo às diversas especialidades, destinado a facilitar a tarefa dos combatentes nas suas diversas funções.

8 Um indício de que a orientação era pra valer é que só o oficial Jair Jordão Ramos publicou 53 artigos na Revista de Educação Física, entre 1936 e 1979, sendo a maior parte deles dedicada à explicitação do projeto pedagógico do Exército para a tropa.

Movimento, Porto Alegre, v. 9, n. 1, p. $91-118$, janeiro/abril de 2003 
A Educação Física no âmbito escolar constitui uma oportunidade da educação, ela [...] constitui a pedra fundamental, integrante e indissociável da educação geral. Nele, por meio de exercícios apropriados e recreação, procura-se desenvolver as aptidões físicas, morais, mentais e sociais do aluno (Ramos, 1953, p. 3). Conforme Magalhães (1939, p. 1), [...] educar fisicamente a mocidade é prepara-la para a prática da obediência e da disciplina.

O sistema de Educação Física a ser utilizado nas escolas deve ser higiênico e prático, sempre que possível ministrado ao ar livre, utilizando os movimentos na procura de generalizar o trabalho a todas as partes do corpo: exercícios destinados a ativar a circulação, a melhorar a função respiratória pela amplitude dos movimentos respiratórios obtidos por via reflexa (Revista de Educação Física, 1938).

Nesse contexto, a Educação Física deve ser corretiva para permitir combater as más atitudes escolares e deve também se apresentar de forma recreativa, dedicando um lugar considerável aos jogos. ${ }^{9}$

A atração dos exercícios nessas lições de Educação Física aplicadas na escola é alcançada pela alternância dos movimentos com a utilização de pequenos jogos individuais ou coletivos.

Dessa forma,

[...] na motivação do trabalho escolarépreciso nãoesquecer a idade eo desenvolvimento físico e mental dos alunos e a necessidade de formar atitudes, hábitos e habilidades que a vida numa sociedade civilizada impõe e exige (Aguayo, 1964, p. 64).

Segundo Aguayo (1964, p. 63-64),

O trabalho escolar está bem motivado quando satisfaz uma necessidade do educando, quando visa a um fim que ele deseja atingir ou dá alguma capacidade que deseja possuir [...] em qualquer caso, porém, desde que ojovem compreenda a relação existente entre o trabalho escolar e o fim colimado, a aprendizagem está motivada. E quanto mais nítida seja essa compreensão e mais intenso o desejo de alcançar o objetivo, mais eficaz será, provavelmente, oresultado da aprendizagem.

\footnotetext{
9 A importância dos jogos é expressa em 31 artigos publicados entre janeiro de 1933 e julho de 1958 por militares e civis. Os oficiais Antônio Pereira Lira, Ivanhoé Gonçalves Martins, Inácio de Freitas Rolim, Jair Jordão Ramos, José de Almeida Neves, llídio Romulo Colônia e o sargento C. B. Lobo escreveram treze artigos. Já os civis Arthur Ramos, Mario Filho, Jair da Graça Raposo, llídio Alcântara Abade, Haydée Costa, Otávio Gonsaga e Neusa Feitál escreveram dez artigos. Ainda foram localizados oito artigos não assinados. Aqui se observa mais um sinal de que 0 trabalho de definição, explicação e prescrição de práticas corporais tanto para civil quanto para militar é feito por cooperação mútua desses segmentos da sociedade. Embora haja evidências no impresso de que, à medida que vão se formando os profissionais civis, os militares vão se afastando da discussão afeta à escolarização do componente curricular Educação Física.
}

Movimento, Porto Alegre, v. 9, n. 1, p. 91-118, janeiro/abril de 2003 
Se tanto as lições aplicadas na escola como no Exército apresentam os mesmos eixos fundamentais e se organizam da mesma forma, começando pela lição preparatória, passando à lição propriamente dita e encerrando com a volta à calma, quais marcas estão materializadas no impresso que podem fazer a distinção?

\section{Sobre a Seção Lição de Educação Física}

A seção Lição de Educação Física foi criada em junho de 1932, na Revista de Educação Física, ano 1, n. 2. O objetivo da sua veiculação era facilitar a divulgação do método regulamentado pelo Exército para o ensino da Educação Física nos meios militar e civil.

As lições são organizadas, em grande parte, por oficiais (capitães e tenentes), mas há uma pequena colaboração de sargentos e civis, como professores, por exemplo. ${ }^{10}$

A lição é dividida em:

F sessão preparatória, cujo objetivo é o aquecimento do organismo, por meio de exercícios respiratórios e de flexibilidade;

F sessão propriamente dita, composta por exercícios pertencentes ao que ficou conhecido como as sete famílias: marchar, trepar, saltar, levantar e transportar, correr, lançar, atacar e defender-se;

F volta à calma, que impõe ao organismo retornar ao seu estado inicial, por meio de exercícios respiratórios com marcha lenta e marcha com canto ou assobio e exercícios de ordem;

e, por último,

F sessão de estudos, cujo objetivo é que os alunos aprendam o melhor modo de execução dos movimentos que entram na composição da Lição (Cavalcanti, 1932, grifo nosso).

10 Autores que escreveram textos sobre a organização das lições de Educação Física: capitão Inácio de Freitas Rolim, capitão José Manoel Ferreia Coelho, capitão Antônio Pires de Castro, capitão Raimundo Simas de Mendonça, tenente Laurentino Lopes Bonorino, primeiro-tenente Osvaldo Niemeyer Lisboa, primeirotenente Lélio de Miranda, primeiro-tenente Alvaro Alves dos Santos, primeirotenente Ivanhoé Gonçalves Martins, primeiro-tenente José de Souza Bastos Júnior, sargento. Paulo Teixeira, professor Idílio Alcântara O. Abade e professora Felisbina Pinheiro Morais.

Movimento, Porto Alegre, v. 9, n. 1, p. 91-118, janeiro/abril de 2003 
Além disso, podem ser introduzidos a essa lição alguns jogos, ${ }^{11}$ com a finalidade de torná-la mais atrativa.

Os resultados indicam que a presente lição é recomendada de forma diferente para militares e para civis. Na lição de Educação Física aplicada aos militares, predomina o uso da ginástica (composta de flexionamentos, dos exercícios educativos e das aplicações), com maior ênfase à lição propriamente dita, isto é, ao item aplicações, que corresponde as sete grandes famílias (Ferreira Neto, 1999).

Os flexionamentos são movimentos de efeitos corretivos e de efeitos localizados sobre as articulações e sobre os músculos que as comandam. Dividem-se em duas categorias: a primeira compreende os flexionamentos dos braços, das pernas, do tronco e da caixa torácica; a segunda reúne os flexionamentos combinados e assimétricos.

Os exercícios educativos têm a função de preparar o sistema nervoso, as articulações e os músculos para a execução correta das aplicações, cuja finalidade é aperfeiçoar todos os meios físicos de que o homem dispõe e que desenvolveu pelos exercícios educativos e pelos flexionamentos. Além disso, as aplicações agem de forma eficaz sobre a formação do caráter, preparando o indivíduo para a solução de atos difíceis de realizar (Ramos, 1938).

É importante ressaltar que a Educação Física Militar é diferente para os que estão ingressando no Exército e para os que já estão inseridos na tropa. Sendo assim, num primeiro momento, ela nada mais é do que a aplicação integral do Regulamento Geral de Educação Física e, num segundo momento, a continuação deste; com o aumento, porém, das aplicações militares que constituem uma parte especializada para o militar (Revista de Educação Física, 1933).

Essa instrução específica para os militares é feita por meio das lições de aplicações militares, que se diferenciam das lições de Educação Física, por terem cunho coletivo, pois sua finalidade é reunir em uma lição a aplicação das sete famílias, porém

11 A respeito da importância dos jogos no desenvolvimento da criança, ver: ROLIM Ignácio. Jogos. Revista de Educação Física, Rio de Janeiro, ano 2, n. 8, p. 3-5, maio de 1933.; MARTINS, Ivanhoé Gonçalves. Educação física infantil. Revista de Educação Física, Rio de Janeiro, ano 2, n. 8, p. 26-27, maio 1933.

Movimento, Porto Alegre, v. 9, n. 1, p. 91-118, janeiro/abril de 2003 
com os homens agrupados em unidades (pelotões, por exemplo), em situações de combate, com obstáculos, armados, fardados, equipados e carregados (Colonia, 1933).

Além do caráter coletivo, elas se diferenciam na seção preparatória, porque as lições de aplicações militares utilizam a marcha prolongada ao invés dos flexionamentos; além disso, a volta à calma é mais longa, pois o esforço nessa lição é maior; os exercícios de ordem são substituídos por exercícios de ordem unida (manejo de armas, por exemplo); o comando posição fundamental deve ser substituído pelo de sentido; não há jogos recreativos entre as lições; as aplicações são feitas uma vez por semana e possuem duração de 20min, no máximo (a comum tem duração de 45min) (Colonia, 1933).

Existe, ainda, na seção Lições de Aplicações Militares, outra divisão: lições aplicadas aos normais e aos poupados (indivíduos que possuem deficiências físicas ou problemas respiratórios). Aos primeiros é aplicado o regime de trabalho do segundo grau do ciclo secundário e aos segundos são ministrados os exercícios aplicados ao primeiro grau do ciclo secundário. ${ }^{12}$

A lição de Educação Física destinada às crianças, ou seja, escolar, prioriza a utilização de jogos, uma vez que não se pode recomendar o mesmo conteúdo, metodologia e avaliação que se utiliza com o soldado e, além disso, devem-se respeitar os regulamentos das instituições escolares e ainda o desenvolvimento psíquico e fisiológico da criança. Sendo assim, as lições são específicas para cada série da Educação Física Elementar (pré-pubertária) e da Educação Física Secundária (pubertária e pós-pubertária).

Assim, enquanto a Educação Física Elementar é dividida em:

F $1^{\circ}$ grau, crianças de 4 a 6 anos;

F $\mathbf{2}^{\circ}$ grau, de 6 a 9 anos;

F $3^{\circ}$ grau, de 9 a 11 anos;

F $4^{\circ}$ grau, de 11 a 13 anos,

a Educação Física Secundária é dividida em:

120 regime de trabalho do segundo grau do Ciclo Secundário é composto por: sessão preparatória, lição propriamente dita (com uma ou duas aplicações dos exercícios das sete famílias) e volta à calma. O regime do primeiro grau Ciclo Secundário é constituído por: sessão preparatória, lição propriamente dita (três exercícios educativos e quatro aplicações).

Movimento, Porto Alegre, v. 9, n. 1, p. 91-118, janeiro/abril de 2003 
F $1^{\circ}$ grau, adolescentes de 13 a 16 anos

F $2^{\circ}$ grau, rapazes e moças de 16 a 18 anos.

Estes limites de idades são determinados em exame médico biométrico feito pelo médico com a colaboração do pedagogo, que completa a classificação com o exame prático que é feito individualmente e sem espírito de competição (Revista de Educação Física, 1938, p. 34).

Os conteúdos das lições de Educação Física para os militares são: a ginástica e, em menor escala, os esportes individuais e coletivos. Já as lições de Educação Física nas escolas, principalmente no Ciclo Elementar, são compostas por jogos e brincadeiras.

Os jogos representam um meio inteligente de tornar a Educação Física atraente, desenvolvendo ao mesmo tempo qualidades corporais. Além disso, eles proporcionam oportunidades para a educação social, promovendo situações reais no mundo do brinquedo (Revista de Educação Física, 1938). Eles são divididos em pequenos jogos (não exigem esforços muito intensos, nem contrações musculares muito localizadas e seus efeitos são essencialmente higiênicos) e grandes jogos de caráter mais recreativo, graças ao prazer que acompanha sua prática e ao fato de serem realizados de forma mais ativa e intensa.

A criança que se acostuma nos jogos a respeitaro direito dos adversários e companheiros, aplicará mais tarde na vida real todos esses bons preceitos (Revista de Educação Física, 1938, p. 34).

Às crianças de quatro a seis anos devem ser ministrados exercícios mímicos, jogos e pequenas evoluções; de seis a nove anos devem ser dadas pequenas evoluções, rodas cantadas, jogos e movimentos de iniciação, exercícios educativos e corretivos, educação respiratória, pequenos jogos coletivos, preparação às aplicações e natação; de treze a dezesseis anos, esse programa é realizado com maior intensidade, iniciando-se a preparação à prática esportiva (Revista de Educação Física, 1938).

Os exercícios mímicos ministrados aos alunos de quatro a seis anos são dados, principalmente, na forma recreativa de ginástica historiada, ${ }^{13}$ que consiste em contar uma história infantil, previa-

\footnotetext{
13 Exemplo de lição de Educação Física dada na forma de ginástica historiada pode ser encontrado em: MORAIS, Felisbina Pinheiro. Educação física infantil: método prático para a realização das lições de educação física (organização da professora Felisbina Pinheiro Morais). Revista de Educação Física, Rio de Janeiro, ano VII, n. 45, p. 29-30, jun./jul. 1939
}

Movimento, Porto Alegre, v. 9, n. 1, p. 91-118, janeiro/abril de 2003 
mente preparada, que abranja os exercícios de uma seção de ginástica comum e que, sempre que possível, inclua ensinamentos de bons hábitos (Revista de Educação Física, 1950).

É importante ressaltar que a ginástica comum presente nas aulas ministradas no Ciclo Elementar possui um grau de dificuldade que respeita a idade biológica dos alunos. Sendo assim, constatou-se que, nas lições dadas sob a forma de ginástica historiada, os exercícios possuem um grau de dificuldade e de rigidez menor do que as aplicadas aos ciclos posteriores.

A maneira de preparar a ginástica infantil não deve ser rígida, devendo, no entanto obedecer na medida do possível, a uma seqüência lógica. A realidade nos ensina que nem sempre se pode seguiro plano pré-estabelecido, havendonecessidade de mudança na ordem e, por vezes, de improvização de exercícios (Revista de Educação Física, 1950, p.16).

A forma de transmissão do conhecimento utilizada pelo Exército, nas lições, é o método da demonstração, ou seja, o instrutor faz, demonstra e os alunos repetem (imitam).

As liçôes devem ser ministradas ao ar livre (estádio, por exemplo), com o tempo bom; e em compartimento coberto e com boa iluminação (ginásio, se houver), em caso de mau tempo (Cavalcanti, 1932).

As lições nas escolas devem ser dadas em horários que não prejudiquem o recreio e nem perturbem a digestão dos alunos. Além disso, deve-se fugir sempre das horas de maior calor e de sol mais forte (Revista de Educação Física, 1938).

No Ciclo Elementar, utilizam-se poucos materiais didáticos e, uma vez que grande parte das lições é dada sob a forma de jogos ou de brincadeiras, o único material encontrado, até o momento, são cordas.

Na Educação Física Secundária para o $1^{\circ}$ grau, são utilizados os materiais didáticos a seguir: cordas duplas, barreira para salto e medicine-ball. Para o $2^{\circ}$ grau, são utilizados: vigas de madeira ou ferro com 30 a $40 \mathrm{~kg}$ e medicine-ball de $4 \mathrm{~kg}$.

Na Educação Física Militar, as lições de Educação Física para o primeiro período de instrução utilizam os seguintes materiais: viga a $2 \mathrm{~m}$ de altura, medicine-ball, bolas, granadas, cordas ou hastes, saco leve para transportar e carregar, peso de $7 \mathrm{~kg}$ e $257 \mathrm{~g}$, prancha inclinada de $45^{\circ}$, grade ou sebe (cerca de arbustos, estacas ou ramos entrelaçados, para vedar terrenos) de $1 \mathrm{~m}$ de altura, pórtico a altura de $7 \mathrm{~m}$, barras duplas, objetos pesados (pedra, por exemplo), vigas de 1,30m de altura, mastros ou árvores, bastões, bambus, cavalo, sarrafos para salto em altura, cabo-de-guerra, correia, trave. Para o

Movimento, Porto Alegre, v. 9, n. 1, p. 91-118, janeiro/abril de 2003 
segundo período de instrução: cabo inclinado, sarrafo para saltos, hastes retas para luta de tração, bambus e granadas.

Nas lições de aplicações militares, os materiais encontrados foram: fuzil (baioneta armada), talude (terreno inclinado), barreira e alvos, varas de salto, sacos de terra, material de esgrima (máscaras, luvas, sabres, mosquetão), chapéus de cavaletes, cabo, pórtico (átrio amplo, com teto sustentado por colunas ou pilares), armas, pás, picaretas, vigotas, maços (martelo de madeira usado por carpinteiros), estacas, arame, duas peças atreladas ou carregadas e manequins.

As roupas para a prática das lições de Educação Física devem ser próprias para as estações do ano, amplas, não comprimindo o tórax, o abdômen, o pescoço, os braços e as pernas (Revista de Educação Física, 1938).

Assim sendo, a análise dessa seção permite dizer que a lição de Educação Física destinada aos alunos das escolas civis é diferente da aplicada aos militares. Constatou-se a existência de seções específicas, como a Lição de Aplicações Militares, composta por exercícios aplicados exclusivamente no Exército, como lançamento de granadas, por exemplo. Já o caráter lúdico característico do conteúdo "jogo e brincadeiras", que é prescrito predominantemente à escola, possui lugar periférico na caserna.

\section{Considerações finais}

Com este estudo, em relação ao ciclo de vida, pôde-se verificar a presença de elementos caracterizadores do periódico em termos de chancela, objetivo, ciclo de vida, periodicidade, formato e colunagem, número de páginas, propriedade, expediente, colaboradores, âmbito de circulação, tiragem, preço (avulso e/ou assinatura, gratuito), preço de espaço publicitário, conteúdo (assuntos recorrentes), iconografia, publicidade e acervos de referência que são fundamentais à compreensão geral do periódico.

Os eixos pedagógicos propostos pelo Exército, como forma de disseminar a Educação Física na sociedade brasileira, são a continuidade, a alternância, a graduação, a atração e a disciplina, os quais se encontram subordinados aos grandes eixos doutrinários existentes no Exército: a hierarquia, a ordem e a disciplina que, por sua vez, orientam toda a ação institucional. Observou-se, ainda, que esses eixos doutrinários e pedagógicos estão presentes tanto na Educação Física aplicada no meio militar

Movimento, Porto Alegre, v. 9, n. 1, p. 91-118, janeiro/abril de 2003 
(Exército) quanto na sociedade civil (Escola). Há evidências em Horta (1994) e em Ferreira Neto (1999) de resistências, conflítos dentro do mesmo campo acadêmico, sem que isso signifique contraposição, oposição de classe social como se foi levado a pensar por uma vertente pouco afeita à pesquisa de fontes, rigor teórico-metodológico; por outro lado, presentista e ideológica da historiografia da Educação Física brasileira. ${ }^{14}$ Tal perspectiva, que é datada, mas subsiste em forma adaptada de retórica, desconhece os essenciais dos fazeres da pesquisa historiográfica em Bloch e especialmente em Ginzburg.

A análise das propostas pedagógicas do Exército levanta o questionamento sobre quais teriam sido as bases teóricas utilizadas como suporte para sua construção. Nesse sentido, há indícios de que a base teórica desses princípios pode ser encontrada no pragmatismo e no funcionalismo visto nas obras de JeanJacques Rousseau, ${ }^{15}$ Willian James, ${ }^{16}$ John Dewey ${ }^{17}$ e Edouard Claparède $^{18}$ (Ferreira Neto, 1999).

Outros dois questionamentos foram suscitados no decorrer desta análise: em relação à presença da Seção Unidade de Doutrina: quais foram os motivos que levaram à sua supressão a partir do n. 8, em abril de 1933, voltando a ser publicada somente em julho de 1938, na revista n. 40, e permanecendo em intervalos irregulares até o n. 47, de dezembro de 1939? Sua extinção, a partir de então, significa que o Exército estaria mudando de doutrina ou que a doutrina divulgada e já estabelecida dispensaria, agora, uma seção específica, mas continuaria a permear cada artigo veiculado pelo periódico?

Com relação à análise da seção Lição de Educação Física, constatou-se que os objetivos, conteúdos, metodologia, recursos físicos e materiais didáticos utilizados nas Lições de Educação Física são diferentes para a instrução militar (Lição de Aplicações Militares) e para o ensino nas escolas.

14 Um diálogo rigoroso com essa produção pode ser encontrado em Oliveira (2001ab). 15 ROUSSEAU, J. J. O emílio ou da educação. 3. ed. São Paulo: Difel, 1979. 569 p. 16 JAMES, W. Pragmatismo e outros textos. Os pensadores. São Paulo: Abril Cultural, 1985. $230 \mathrm{p}$

17 DEWEY, J. Democracia e educação. 2. ed. São Paulo: Companhia Editora Nacional, 1952. 470 p.; DEWEY, J. Vida e educação. 11. ed. São Paulo: Melhoramentos, 1978. $113 \mathrm{p}$.

18 CLAPARÈDE, E. A educacão funcional. 3. ed. São Paulo: Companhia Editora Nacional, 1958. 302 p.; CLAPARÈDE, E. A escola sob medida. Rio de Janeiro: Fundo de Cultura, 1959. 207 p.

Movimento, Porto Alegre, v. 9, n. 1, p. 91-118, janeiro/abril de 2003 
Nas lições aplicadas aos militares, os objetivos têm caráter estritamente militar, ou seja, as lições são uma simulação de situações de combate, visando à preparação da tropa. Os conteúdos das aulas dão maior ênfase ao item aplicações, que corresponde as sete grandes famílias da lição; os recursos físicos utilizados também estão de acordo com os objetivos determinados, assim, são usados campos com obstáculos, cerca de arbustos, terrenos inclinados. Observou-se, ainda, que os materiais, em parte, também são de uso estritamente militar, como granadas e fuzis.

As lições destinadas aos escolares possuem como objetivos o robustecimento do corpo, a educação respiratória e o ensino de bons hábitos; seu conteúdo prioriza a utilização de jogos e brincadeiras; são ministradas em estádios ou ginásios; e os materiais didáticos usados, em sua maioria, são os que auxiliam nas brincadeiras, como cordas.

Os indícios de que há diferenciação nas lições propostas para os militares e para os escolares geram polêmica e carecem de demonstração, uma vez que grande parte das referências bibliográficas sobre o assunto não reconhecem esse fato. Todavia, também, está evidente que as interpretações homogeinizadoras sobre a matéria tendem a se situarem no campo da retórica e não no da História.

\section{Magazine of physical education: cycle of life, sections unit of doctrine and lesson of physical education (1932-2002)}

Abstract: It intends to elaborate the cycle of life of the Magazine of Physical Education from 1932 to 2002; to analyze the sections Unit of Doctrine and Lesson of Physical Education, identifying the doctrinal and pedagogical axis, and the way they are prescribed and practiced in the army and in the schools. The theoretical and methodological orientation take on the periodical as object and source. The results show the characteristics of the periodical materialized in the cycle of life. The pedagogical axis are: continuity, alternation, graduation, attraction and discipline, which are subordinated to the doctrinal axis: hierarchy, order and discipline. The Lesson of Physical Education to military is different from that one to students.

Keywords: Physical Education, Periodicals, Army, Schools.

Movimento, Porto Alegre, v. 9, n. 1, p. 91-118, janeiro/abril de 2003 


\section{Revista de educacion fisica: ciclo de vida, seção unidade de doutrina e lição de educação física (1932-2002)}

Resumen: El objetivo es elaborar el ciclo de vida de la Revista de "Educação Física", durante el período 1932 a 2002; analizar las secciones "Unidade de Doutrina e Lição de Educação Física", identificando los ejes doctrinarios y pedagógicos y también como son prescritos y practicados en el Ejército y en la Escuela. La orientación teórico-metodológica asume el periódico como objeto y fuente. Los resultados indican las características de la publicación, materializadas en el ciclo de vida. Los ejes pedagógicos son: continuidad, alternancia, graduación, atracción y disciplina, que se hallan subordinados a los ejes doctrinarios: jerarquía, orden y disciplina. La lección de Educación Fisica es diferente para militares e escolares.

Palabras-clave: Educación Física, Periódico, Ejército, Escuelas.

\section{Referências}

ABREU, J. R. Toledo de. Um ano de atividade. Revista de Educação Física, Rio de Janeiro, ano 2, n. 12, p. 1, nov. 1933.

A criação da Escola de Educação Física do Exército. Revista de Educação Física, Rio de Janeiro, ano 2, n.12. p. 2-3, nov. 1933.

A Escola de Educação Física do Exército: uma das realizações da inteligência e da tenacidade brasileira. Revista de Educação Física, Rio de Janeiro, ano X, n. 49 , p. $3-8$, nov. 1941

AGUAYO, A. M. Pedagogia científica: psicologia e direção da aprendizagem. São Paulo: Companhia Editora Nacional, 1964.

BERCITO, Sonia de Deus Rodrigues. Ser forte para fazer a nação forte: a educação física no Brasil (1932-1945). 1991. 244 f. Dissertação (Mestrado em História Social) - Departamento de História da Faculdade de Filosofia, Letras e Ciências Humanas da Universidade de São Paulo, São Paulo, 1991.

BICCAS, Maurilane de Souza. O impresso como estratégia de formação de professores(as) e de conformação do campo pedagógico em Minas Gerais: o caso da Revista do Ensino 1925-1940).2001. 311 f. Tese (Doutorado em Educação - História da Educação e Historiografia) - Faculdade de Educação da Universidade de São Paulo, São Paulo, 2001.

BLOCH, Marc. Apologia da história: ou o ofício de historiador. Rio de Janeiro: Jorge Zahar Editor, 2001.

CALMON, Pedro. Uma política de cultura! Revista de Educação Física, Rio de Janeiro, ano VI, n. 40, p. 1, jul. 1938.

Movimento, Porto Alegre, v. 9, n. 1, p. 91-118, janeiro/abril de 2003 
CARDOSO, Ciro Flamarion; VAINFAS, Ronaldo. História e análise de textos. In:_ (Orgs.). Domínios da história: ensaios de teoria e metodologia. Rio de Janeiro: Campus, 1997. cap. 17, p. 375-401.

CARDOSO, Dulcidio. Mens sana in corpore sano. Revista de Educação Física, Rio de Janeiro, ano 2, n. 9, p. 1, jun. 1933.

CATANI, Denice Bárbara. Educadores à meia-luz: um estudo sobre a Revista de Ensino da Associação Beneficente do Professorado Público de São Paulo 1902-1919. 1989. Tese (Doutorado em Educação) - Faculdade de Educação da Universidade de São Paulo, São Paulo, 1989.

CATANI, Denice Bárbara. Ensaios sobre a produção e circulação dos saberes pedagógicos. 1994. Tese (Livre Docência) - Faculdade de Educação da Universidade de São Paulo, São Paulo, 1994.

CATANI, Denice Bárbara. Perspectivas de investigação e fontes para a história da educação brasileira: a imprensa periódica educacional. In: ____ (Orgs.). Ensaios sobre a produção e circulação dos saberes pedagógicos. São Paulo: Dedalus, 1994. p. 58-76.

CATANI, Denice Bárbara; BASTOS, Maria Helena Câmara (Orgs.). Educação em revista: a imprensa periódica e a história da educação. São Paulo: Escrituras, 1997.

CATANI, Denice Bárbara; SOUSA, Cynthia Pereira de. (Orgs.). Imprensa periódica educacional paulista (1890-1996): catálogo. São Paulo: Plêiade, 1999.

CATANI, Denice Bárbara; SOUSA, Cynthia Pereira de. O catálogo da imprensa periódica educacional paulista (1890-1996): um instrumento de pesquisa. In: (Orgs.). Imprensa periódica educacional paulista (1890-1996): catálogo. São Paulo: Plêiade, 1999. p. 9-30.

CAVALCANTI, Newton. Unidade de doutrina. Revista de Educação Física, Rio de Janeiro, ano 1, n. 2, jun. 1932a.

CAVALCANTI, Newton. Unidade de doutrina. Revista de Educação Física, Rio de Janeiro, ano 1, n. 3, jul. 1932b.

COLONIA, Ilidio Romulo. Unidade de doutrina. Revista de Educação Física, Rio de Janeiro, ano 2, n. 4, jan. 1933.

COLONIA, Ilidio Romulo. Unidade de doutrina: aplicações militares. Revista de Educação Física, Rio de Janeiro, ano 2, n. 6, mar. 1933.

CRUZ, Heloísa de Faria (Org.). São Paulo em revista: catálogo de publicações da imprensa cultural e de variedades paulistana 1870-1930. São Paulo: Arquivo do Estado, 1997.

DEWEY, John. Vida e educação. São Paulo: Melhoramentos, 1978.

EDITORIAL. Revista de Educação Física, Rio de Janeiro, ano XXVIII, n. 93, p. 1, jan. 1964.

EDUCAÇÃo física infantil. Revista de Educação Física, Rio de Janeiro, ano XVIII, n. 65/66, p. 16-17, 1950.

ESTADO Maior do Exército. Regulamento de Educação Física (3ª parte). Rio de Janeiro: Biblioteca de A Defesa Nacional, 1934.

FERREIRA Neto, Amarílio. A pedagogia no exército e na escola: a educação física brasileira (1880 - 1950). Aracruz, ES: FACHA, 1999.

Movimento, Porto Alegre, v. 9, n. 1, p. 91-118, janeiro/abril de 2003 
FERREIRA Neto, Amarílio et al. Catálogo de periódicos de educação física e esporte (1930 - 2000). Vitória: PROTEORIA, 2002.

GINZBURG, Carlo. A micro-história e outros ensaios. Lisboa: Difel, 1991.

GINZBURG, Carlo. Mitos, emblemas, sinais: morfologia e história. São Paulo: Companhia das Letras, 1999.

GINZBURG, Carlo. Olhos de madeira: nove reflexões sobre a distância. São Paulo: Companhia das Letras, 2001.

GINZBURG, Carlo. Relações de força: história, retórica, prova. São Paulo: Companhia das Letras, 2002.

GOELLNER, Silvana Vilodre. Bela, maternal e feminina: imagens da mulher na revista Educação Physica. 1999. 187 f. Tese (Doutorado em Educação) Programa de Pós-Graduação em Educação, Universidade Estadual de Campinas, Campinas,1999.

GOMES, Ângela Maria de Castro. Notas sobre uma experiência de trabalho com fontes: arquivos privados e jornais. Revista Brasileira de História, São Paulo, ano 1, n. 2, p. 259-283, set.1981.

HORTA, José Silvério Baia. O hino, o sermão e a ordem do dia: Regime autoritário e a educação no Brasil (1930-1945). Rio de Janeiro: Ed. UFRJ, 1994.

LIMA, Magali Alonso de. O corpo no espaço e no tempo: a educação física no Estado Novo (1937-1945). 1980. 155 f. Dissertação (Mestrado em Educação) Instituto de Estudos Avançados em Educação da Fundação Getúlio Vargas, Rio de Janeiro, 1980.

LOPES, Eliane Marta Teixeira; GALVÃO, Ana Maria de Oliveira. Fontes e história da educação. In: 2001. cap. III, p. 77-96. . História da educação. Rio de Janeiro: DP\&A,

MAGALHAES, Fernando. Editorial. Revista de Educação Física, Rio de Janeiro, ano VII, n. 47, p. 1, dez. 1939.

MARTINS, Ana Luiza. Revistas em revista: imprensa e práticas culturais em tempos de República, São Paulo (1890-1922). São Paulo: Edusp; Fapesp; Imprensa Oficial do Estado, 2001.

MOLINA, Antônio de Mendonça. Importância da educação física para um povo: o metodo adotado. Revista de Educação Física, Rio de Janeiro, ano 1, n. 3, jul. 1932.

NUNES, Clarice. Interrogando a avaliação dos trabalhos de história da educação: o inventário de uma prática. In: Reuniăo Anual Da Associação Nacional De Pósgraduação E Pesquisa Em Educação, 24., 2001, Caxambu. Anais eletrônicos... Disponível em: http://www.edu.uerj.br/gthe/frame.htm. Acesso em: 12 mar. 2003. GTT2.

OLIVEIRA, Marcus Aurélio Taborda de. A Revista Brasileira de Educação Física e Desportos (1968-1984) e a experiência cotidiana de professores da rede municipal de ensino de Curitiba: entre a adesão e a resistência. 2001. Tese (Doutorado em Educação: História, Política, Sociedade) - Pontifícia Universidade Católica de São Paulo, São Paulo, 2001a.

OLIVEIRA, Marcus Aurélio Taborda de. Para uma crítica da historiografia: ditadura militar, educação física e negação da experiência do professor. In: Ferreira Neto, Amarílio (Org.). Pesquisa histórica na educação física. Vitória: PROTEORIA, 2001b. p. 5-48.

Movimento, Porto Alegre, v. 9, n. 1, p. 91-118, janeiro/abril de 2003 
PEREIRA, Augusto Heleno Ribeiro.Editorial. Revista de Educação Física, Rio de Janeiro, n. 125, p. 3, 2001.

PINHEIRO, João Ribeiro. A inquietação espiritual e a educação física. Revista de Educação Física, Rio de Janeiro, ano 2, n. 5, fev. 1933a.

PINHEIRO, João Ribeiro. A pedagogia e a educação fisica. Revista de Educação Física, Rio de Janeiro, ano 2, n. 6, mar. 1933b.

PINHEIRO, João Ribeiro. Dia glorioso. Revista de Educação Física, Rio de Janeiro, ano 2, n. 4, jan. 1933c.

RAMOS, Jair Jordão. Secção Pedagógica. Revista de Educação Física, Rio de Janeiro, ano VI, n. 40, p. 38, jul. 1938.

PINHEIRO, João Ribeiro. Secção pedagógica finalidade: unidade e doutrina. Revista de Educação Física, Rio de Janeiro, ano VI, n. 42, p. 52, set. 1938.

PINHEIRO, João Ribeiro. Finalidade: unidade de doutrina. Revista de Educação Física, Rio de Janeiro, ano VII, n. 47, p. 11-12, dez. 1939.

PINHEIRO, João Ribeiro. Conceitos e sugestões. Revista de Educação Física, Rio de Janeiro, ano XX, n. 75, p. 3, out. 1953.

RODRIGUES, Elton Geyer.Editorial. Revista de Educação Física, Rio de Janeiro, n. 124, p. $3,2000$.

SCHNEIDER, Omar. A revista de educação physica (1932-1945): estratégias editoriais e prescrições educacionais. 2003. 344 f. Dissertação (Mestrado em Educação: História, Política, Sociedade) - Pontifícia Universidade Católica de São Paulo, São Paulo, 2003.

Segunda conferencia realizada pela divisão de educação física para os inspetores de ensino. Revista de Educação Física, Rio de Janeiro, ano VI, n. 43, p. 35-37, out. 1938.

Unidade de doutrina: educação física militar. Revista de Educação Física, Rio de Janeiro, ano 2, n. 5, fev. 1933. 